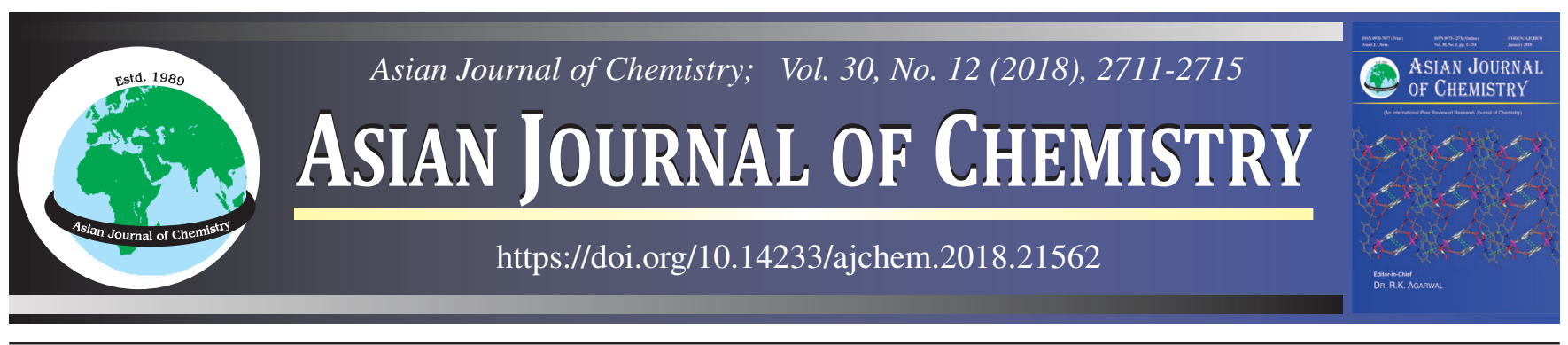

\title{
Brassica oleracea Mediated Synthesis of Zinc Oxide Nanoparticles and its Antibacterial Activity against Pathogenic Bacteria
}

\section{S. Rajeshiumar ${ }^{1, *}$, Happy Agarwal ${ }^{2}$, S. VenKat Kumar ${ }^{2}$ and T. Lakshmi ${ }^{1}$}

${ }^{1}$ Department of Pharmacology, Saveetha Dental College and Hospitals, Saveetha Institute of Medical and Technical Sciences, Chennai-600 077, India

${ }^{2}$ Department of Biotechnology, School of Biosciences and Technology, Vellore Institute of Technology, Vellore-632 014, India

*Corresponding author: E-mail: ssrajeshkumar@hotmail.com

Received: 5 July 2018;

Accepted: 24 August 2018;

Published online: 31 October 2018;

AJC-19136

Green synthetic methods of nanoparticles are simple, non-toxic and environmentally benign process which decline the demerits of conventional physical and chemical methods. The current study focusses on the synthesis of zinc oxide nanoparticles using fresh Brassica oleracea extract. Zinc oxide nanoparticles were characterized using UV-vis spectrophotometry, which showed exciton absorption peak at $380 \mathrm{~nm}$. X-ray diffraction analysis, scanning electron microscopy, atomic force microscopy, energy dispersive X-ray analysis and thermogravimetric analysis were used to determine the shape, size, crystallinity and purity of nanoparticles. The antibacterial activity of zinc oxide nanoparticles was determined by agar well diffusion method against Gram-positive and Gram-negative bacteria

Keywords: Zinc oxide nanoparticles, Green synthesis, Brassica oleracea extract, Antibacterial activity.

\section{INTRODUCTION}

Nano-sized materials are known to play important role in basic and applied sciences thus the metal and metal oxide nanoparticles have been intensively studied in the past decade [1,2]. The metal oxides particularly exhibit fascinating properties such as electronic, catalytic, magnetic and antimicrobial activity owing to their large surface area to volume ration due to a high fraction of atoms [3,4]. Zinc oxide nanoparticles have a wide band gap of $3.3 \mathrm{eV}$ at room temperature and high excitation binding energy of $60 \mathrm{meV}$, which helps it to demonstrate outstanding catalytic, optical, photochemical and electronic properties [5,6]. Zinc oxide nanoparticles are known to possess unique UV filtering, antibacterial, antifungal properties also which leads to its extensive use in cosmetic and healthcare industries [7-9]. Previous studies suggest that the strong antibacterial activity of zinc oxide nanoparticles against a variety of pathogenic Gram-positive and Gram-negative bacteria attributed to its capacity of releasing $\mathrm{Zn}^{2+}$ ion from $\mathrm{ZnO}$ complex and interruption of lipid bilayer integrity, ROS generation and subsequent damage to DNA and protein of the host cell $[10,11]$. Chemical and physical methods of nanoparticle synthesis have been replaced by feasible eco-friendly alternatives like nanoparticle synthesis using microorganisms, organic sugar, starch, enzymes and plants $[12,13]$. Plants extracts act as a reservoir of several pharmacologically active metabolites and allow the synthesis of nanoparticles in well-defined size and shape controlled manner [14]. Brassica oleracea contains a wide range of biologically active compounds like glucosinolates, polyphenols, alkaloids, flavonoids and micronutrients such as vitamin C, carotene and folic acid-fibers [15]. The present work aims to investigate the role of Brassica oleracea extract in synthesis and stabilization of $\mathrm{ZnO}$ nanoparticles. The morphology and crystal structure were characterized using UV-visible spectroscopy, X-ray diffraction (XRD), scanning electron microscopy (SEM), atomic force microscopy (AFM), energy dispersive X-ray analysis (EDAX) and thermogravimetric analysis (TGA). The antibacterial activity of zinc oxide nanoparticles was evaluated using agar well-diffusion method against Escherichia coli and Streptococcus pyogenes and Rhizobacteria.

\section{EXPERIMENTAL}

UV-visible spectrophotometer with a wavelength range of 300-700 nm was used for confirmation of nanoparticle syn-

This is an open access journal, and articles are distributed under the terms of the Creative Commons Attribution-NonCommercial 4.0 International (CC BY-NC 4.0) License, which allows others to copy and redistribute the material in any medium or format, remix, transform, and build upon the material, as long as appropriate credit is given and the new creations are licensed under the identical terms. 
thesis. X-ray diffractometer operating at $30 \mathrm{~mA}$ and $40 \mathrm{kV}$ was used to determine the purity and crystallinity of the nanoparticles. SEM analysis was conducted to analyze the surface morphology of the nanoparticles. Nanoparticles were sputtered on a carbon coated copper grid for EDAX analysis. AFM was used to determine the particle size and distribution of the nanoparticles. TGA analysis was done to analyze the change in a physical and chemical property of biosynthesized zinc oxide nanoparticles with temperature.

Preparation of $\boldsymbol{B}$. oleracea extract: Brassica oleracea $(10 \mathrm{~g})$ was washed with running tap water and then rinsed with Milli-Q water. Leaves were dried, chopped and soaked in $100 \mathrm{~mL}$ Milli-Q water. The solution was boiled at $60^{\circ} \mathrm{C}$ for $30 \mathrm{~min}$ and then allowed to cool at room temperature. Brassica oleracea extract was filtered through Whatman filter paper No. 1 and the filtrate were stored at $4{ }^{\circ} \mathrm{C}$ for analyses [16].

Biosynthesis of $\mathrm{ZnO}$ nanoparticles: Brassica oleracea extract $(25 \mathrm{~mL})$ was added to $75 \mathrm{~mL}$ of $1 \mathrm{mM}$ of zinc sulfate solution in a $250 \mathrm{~mL}$ Erlenmeyer flask and the reaction mixture was incubated at $80^{\circ} \mathrm{C}$ for $24 \mathrm{~h}, 100 \mathrm{rpm}$. Reduction of zinc ions to zinc nanoparticles was confirmed using visual observation and UV-visible spectroscopy after $24 \mathrm{~h}$. ZnO nanoparticles were collected by centrifuging the reaction mixture at $8000 \mathrm{rpm}$ for $15 \mathrm{~min}$. $\mathrm{ZnO}$ nanoparticles were double washed using Milli$\mathrm{Q}$ water and then overnight dried in a hot air oven. Obtained $\mathrm{ZnO}$ nanoparticles was used for characterization.

Antibacterial activity of zinc oxide nanoparticles: The agar-well diffusion method was used to determine the antibacterial activity of $\mathrm{ZnO}$ nanoparticles. Different concentration of zinc oxide nanoparticles was tested against Escherichia coli (Gram -ve), Streptococcus pyogenes (Gram +ve) and Rhizobacteria. The fresh bacterial suspension was dispersed on the surface of nutrient agar plates. Different concentration of nanoparticles $(20,40$ and $60 \mu \mathrm{L})$ was incorporated into the wells and the plates were incubated at $37^{\circ} \mathrm{C}$ for $24 \mathrm{~h}$. Ampicillin was used as positive control. Zone of inhibition was recorded in each plate [17].

\section{RESULTS AND DISCUSSION}

UV-visible analysis: UV-visible absorption spectroscopy is widely used for the confirmation of nano-sized particles. Fig. 1 shows strong exciton absorption peak at $380 \mathrm{~nm}$ wavelength which confirmed the synthesis of zinc oxide nanoparticles synthesized from Brassica oleracea extract, which is in good agreement with green synthesis of zinc oxide nanoparticles using Pongamia pinnata and Cassia fistula $[18,19]$.

XRD analysis: X-ray diffraction analysis was conducted to confirm zinc oxide phase of the nanoparticles. The XRD peak identified at (100) reflection at $31.74^{\circ}$ can be indexed to the spherical zinc oxide phase (Fig. 2). Result obtained was in agreement with the data from JCPDS file and lemon leaf mediated zinc oxide nanoparticles [20]. The crystalline structure of the particles was confirmed by the strong diffraction peak obtained.

SEM and EDX analysis: SEM analysis was conducted to study the morphology of nanostructures. Some agglomerates particles were also found. SEM image suggests the synthesis of $\mathrm{ZnO}$ nanoparticles with an average size of about $80 \mathrm{~nm}$ (Fig. 3A). The signal characteristic peak of only zinc and oxygen was further analyzed using EDAX analysis. Presence of $\mathrm{Zn}$

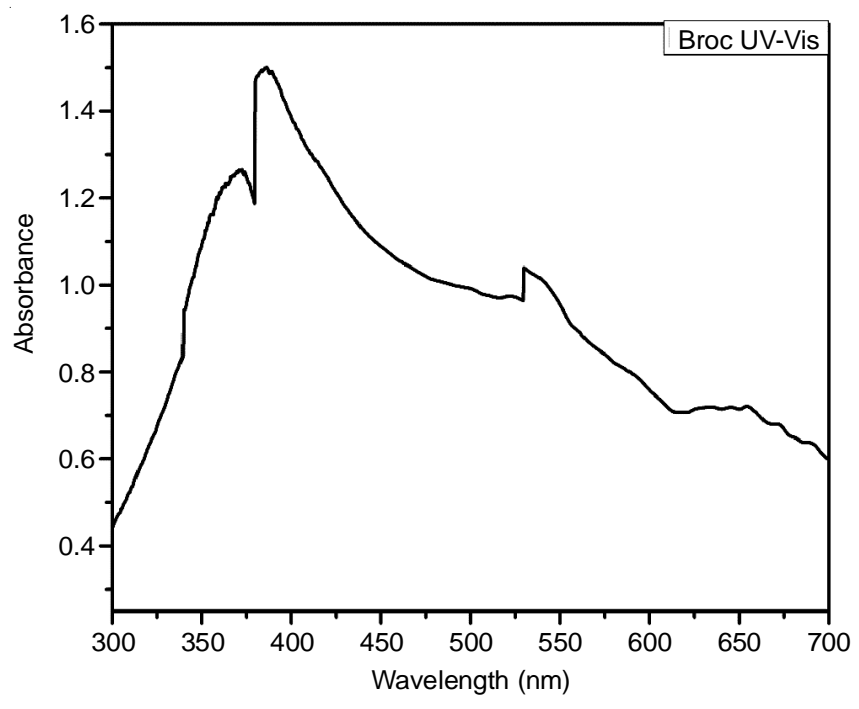

Fig. 1. UV-visible spectrum of zinc oxide nanoparticles

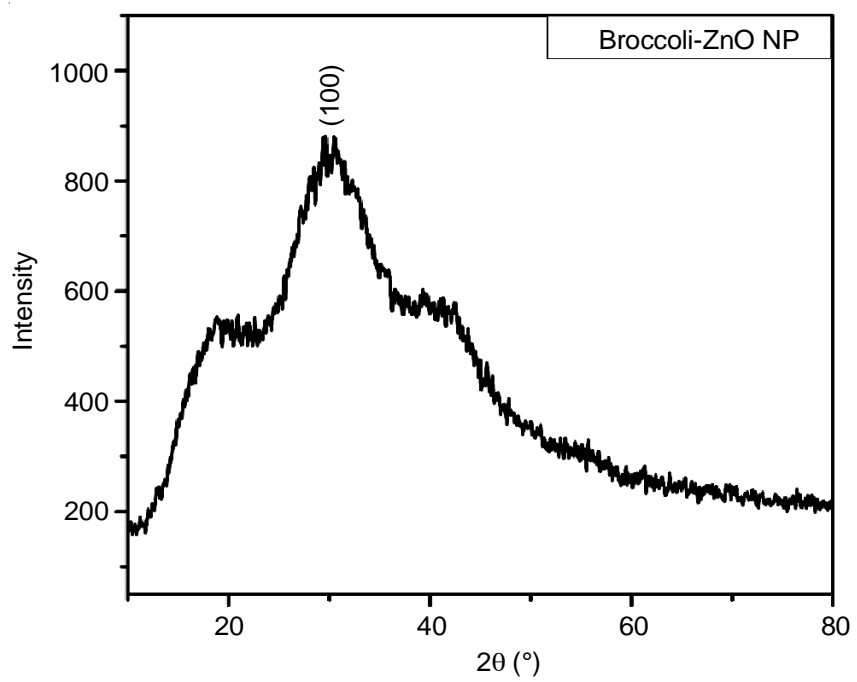

Fig. 2. XRD spectra of $B$. oleracea extract synthesized $\mathrm{ZnO}$ nanoparticles

and $\mathrm{O}$ alone without any unknown signals suggests the purity of $\mathrm{ZnO}$ nanoparticles (Fig 3B). The results obtained are in accordance with root extract of Zingiber officinale assisted green synthesized metal oxide nanoparticles [21].

AFM analysis: The topography of Brassica oleracea synthesized zinc oxide nanoparticles were recorded using AFM analysis (Fig. 4). AFM analysis revealed the monodispersed nature and spherical shape of $\mathrm{ZnO}$ nanoparticles. The zinc oxide nanoparticles synthesized using Passiflora indica also in agreement with the present results [22].

TGA analysis: Thermogravimetric analysis (TGA) analysis revealed the changes in physical and chemical property of the biosynthesized zinc oxide nanoparticles at room temperature to $800^{\circ} \mathrm{C}$ at $20^{\circ} \mathrm{C} / \mathrm{min}$. Thermogram of synthesized $\mathrm{ZnO}$ nanoparticles has been shown in Fig 5. The curve represents mass loss between $30-120^{\circ} \mathrm{C}$ by $9.453 \%$ due to evaporation of surface water. The mass loss continues up to $500{ }^{\circ} \mathrm{C}$ by the rate of $50.65 \%$.

Antibacterial activity of zinc oxide nanoparticles: Antibacterial activity $\mathrm{ZnO}$ nanoparticles were tested against the bacterial pathogens Escherichia coli, Streptococcus pyogenes and Rhizobacteria by agar well diffusion method and the zone of inhibition 

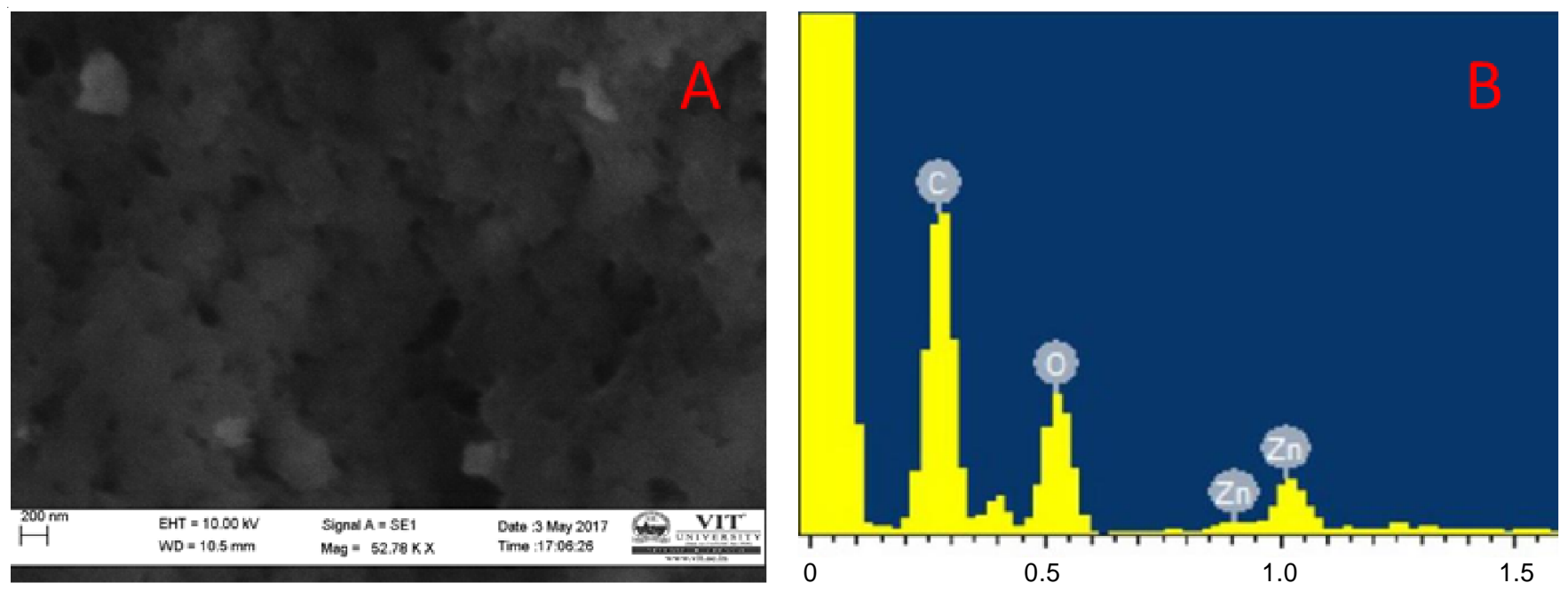

Fig. 3. (A) SEM micrograph of $\mathrm{ZnO}$ nanoparticle (B) EDAX of $\mathrm{ZnO}$ nanoparticle
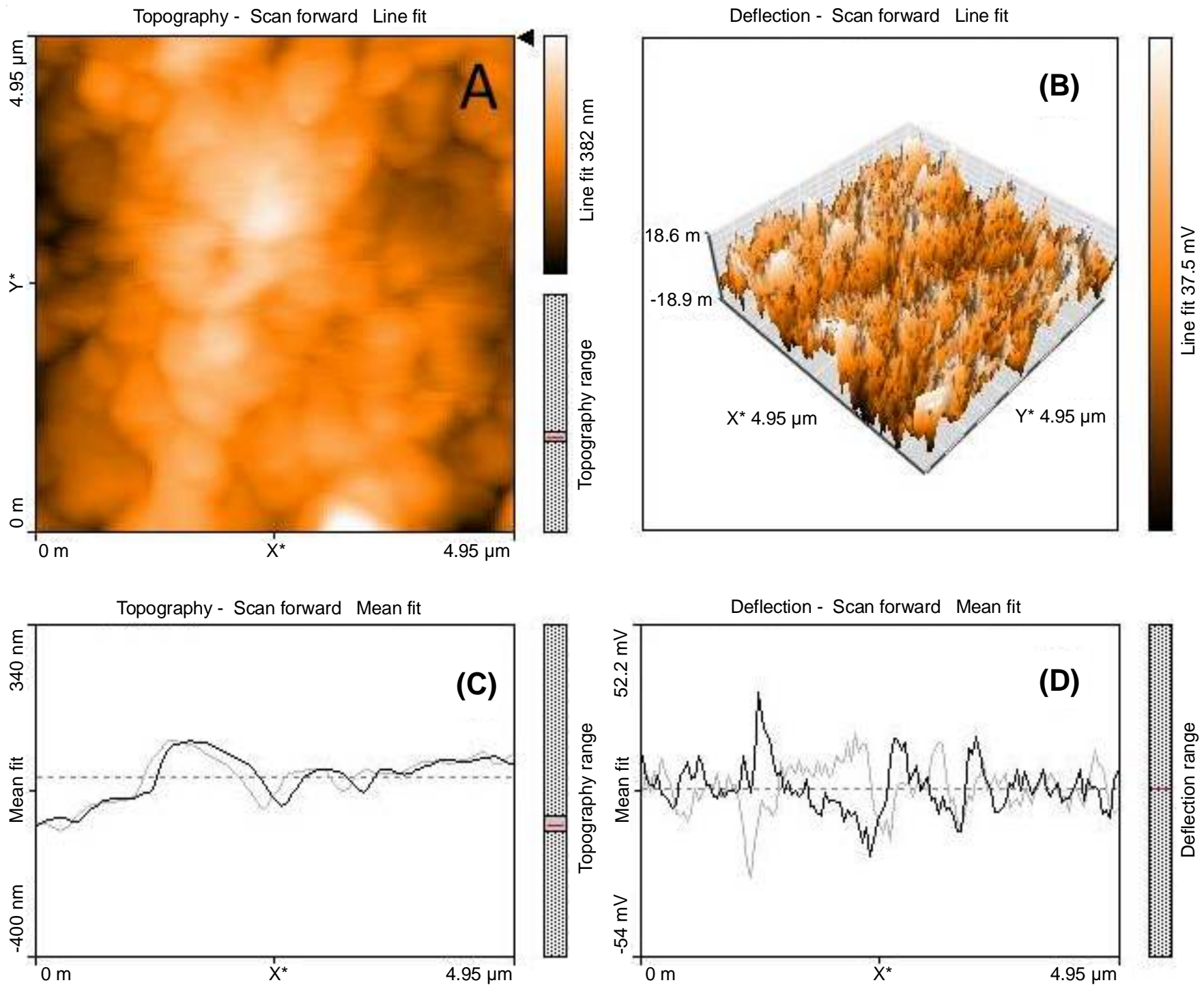

Fig 4. AFM results of zinc oxide nanoparticles (A) Topographical 2D image of zinc oxide nanoparticles (B) 3D image of the zinc oxide nanoparticles. (C) \& (D) particle size distribution

values were determined. The highest zone of inhibition was found in Rhizobacteria with a zone diameter of $28 \mathrm{~mm}$ at 60 $\mu \mathrm{L}$ concentration and the lowest zone of inhibition was found to occur for Escherichia coli at a concentration of $20 \mu \mathrm{L}$. Moderate zones of inhibition were observed for Streptococcus pyogenes at all the concentrations. The plants are the major sources used 
TABLE-1

GREEN SYNTHESIS OF ZINC OXIDE NANOPARTICLES DIFFERENT PLANT EXTRACT

\begin{tabular}{|c|c|c|c|c|}
\hline S. No. & Name of the plant & Size $(\mathrm{nm})$ & Shape & Ref \\
\hline 1 & Azadirachta indica & $20-45$ & Hexagonal & {$[25]$} \\
\hline 2 & Cassia fistula & $5-15$ & Hexagonal and sponge like irregular shape & {$[18]$} \\
\hline 3 & Solanum nigrum & $20-30$ & Hexagonal quasi-spherical & [26] \\
\hline 4 & Moringa oleifera & $16-20$ & Hexagonal & [27] \\
\hline 5 & Nephelium lappaceum & 50 & Needle-shaped and hexagon & [28] \\
\hline 6 & Couroupita guianensis Aubl. & Not mentioned & Nanoflakes & [29] \\
\hline 7 & Pongamia pinnata & $30.4-40.8$ & Spherical & [30] \\
\hline 8 & Caltropis procera & $90-100$ & Not mentioned & [31] \\
\hline 9 & Carica papaya & 11 & Nano-flower & [32] \\
\hline 10 & Plectranthus barbatus & $30-60$ & Spherical & [33] \\
\hline 11 & Mangifera indica & $45-60$ & Spherical and hexagonal quartzite & [34] \\
\hline 12 & Brassica oleracea & 80 & Spherical & This work \\
\hline
\end{tabular}

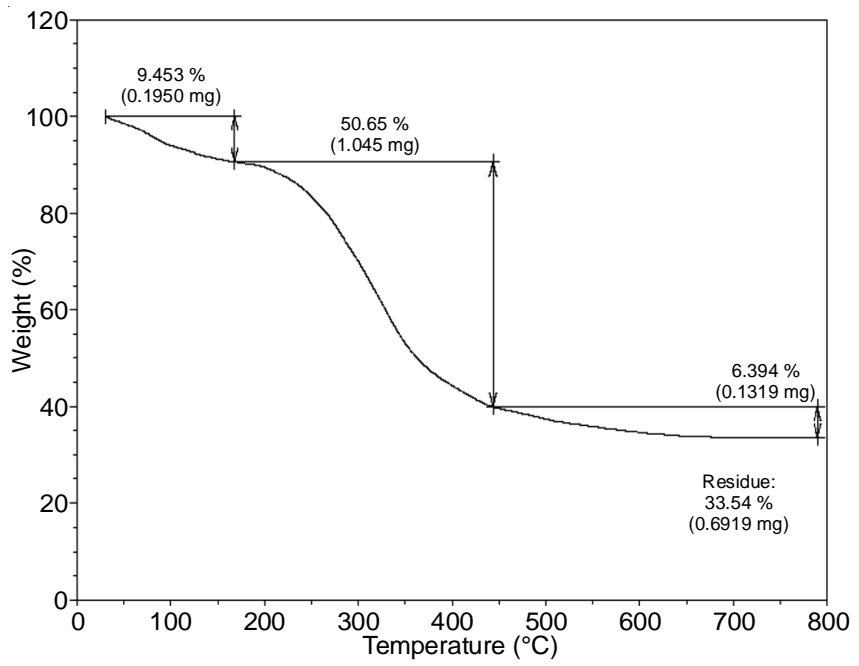

Fig. 5. Thermogravimetric analysis of synthesized $\mathrm{ZnO}$ NPs

for the synthesis of zinc oxide nanoparticles with different shape and size is shown in Table-1. Therefore, the present finding clearly suggests the potential application of Brassica oleracea extract prepared $\mathrm{ZnO}$ nanocrystals as an excellent antibacterial agent. The zinc oxide nanoparticles are actively involved in the antibacterial activity and may used for different types of biomedical applications based on this property [10,22-24].

\section{Conclusion}

In the present study, zinc oxide nanoparticles were synthesized using Brassica oleracea extract and characterized using UV-visible spectroscopy, XRD, SEM, EDAX, AFM and TGA. SEM analysis revealed the synthesis of spherical nanoparticle with individual particle size range of $80 \mathrm{~nm}$ and formation of aggregates. The $\mathrm{ZnO}$ nanoparticles were found to have spherical structure with an absorption maximum at $380 \mathrm{~nm}$ assigned to the intrinsic band-gap absorption. XRD and EDAX confirmed the synthesis of pure crystalline $\mathrm{ZnO}$ nanoparticles. AFM suggested the monodispersed nature of $\mathrm{ZnO}$ nanoparticles. Effect of $\mathrm{ZnO}$ nanoparticles for their antibacterial potential was tested against Escherichia coli, Streptococcus pyogenes and Rhizobacteria by agar-well diffusion method, which showed good activity against all the three tested bacterial pathogens. This study conclusively reports an eco-friendly approach for the synthesis of zinc oxide nanoparticles and highlights its potential to be used as an effective antibacterial agent.

\section{CONFLICT OF INTEREST}

The authors declare that there is no conflict of interests regarding the publication of this article.

\section{REFERENCES}

1. H.R. Madan, S.C. Sharma, Udayabhanu, D. Suresh, H. Nagabhushana, Y.S. Vidya, H. Rajanaik, K.S. Anantharaju, S.C. Prashantha and P.S. Maiya, Spectrochim. Acta A Mol. Biomol. Spectrosc., 152, 404 (2016); https://doi.org/10.1016/j.saa.2015.07.067.

2. B.N. Singh, A.K.S. Rawat, W. Khan, A.H. Naqvi and B.R. Singh, PLoS One, 9, e106937 (2014); https://doi.org/10.1371/journal.pone.0106937.

3. M. Gharagozlou, Z. Baradaran and R. Bayati, Ceram. Int., 41, 8382 (2015);

https://doi.org/10.1016/j.ceramint.2015.03.029.

4. N. Savithramma and G. Bhumi, Int. J. Drug Dev. Res., 6, 208 (2014).

5. F.T. Thema, E. Manikandan, M.S. Dhlamini and M. Maaza, Mater. Lett., 161, 124 (2015);

https://doi.org/10.1016/j.matlet.2015.08.052.

6. R.M. Tripathi, A.S. Bhadwal, R.K. Gupta, P. Singh, A. Shrivastav and B.R. Shrivastav, J. Photochem. Photobiol. B, 141, 288 (2014); https://doi.org/10.1016/j.jphotobiol.2014.10.001.

7. S. Ambika and M. Sundrarajan, J. Photochem. Photobiol. B, 146, 52 (2015); https://doi.org/10.1016/j.jphotobiol.2015.02.020.

8. L. Fu and Z. Fu, Ceram. Int., 41, 2492 (2015); https://doi.org/10.1016/j.ceramint.2014.10.069.

9. T. Bhuyan, K. Mishra, M. Khanuja, R. Prasad and A. Varma, Mater. Sci. Semicond. Process., 32, 55 (2015); https://doi.org/10.1016/j.mssp.2014.12.053.

10. H. Agarwal, S. Menon, S. Venkat Kumar and S. Rajeshkumar, Chem. Biol. Interact., 286, 60 (2018); https://doi.org/10.1016/j.cbi.2018.03.008.

11. S. Gunalan, R. Sivaraj and V. Rajendran, Prog. Nat. Sci. Mater. Int., 22, 693 (2012);

https://doi.org/10.1016/j.pnsc.2012.11.015.

12. Shamsuzzaman, A. Mashrai, H. Khanam and R.N. Aljawfi, Arab. J. Chem., 10 (Suppl. 2), s1530 (2017); https://doi.org/10.1016/j.arabjc.2013.05.004.

13. S. Azizi, M.B. Ahmad, F. Namvar and R. Mohamad, Mater. Lett., 116, 275 (2014); https://doi.org/10.1016/j.matlet.2013.11.038.

14. M. Anbuvannan, M. Ramesh, G. Viruthagiri, N. Shanmugam and N. Kannadasan, Mater. Sci. Semicond. Process., 39, 621 (2015); https://doi.org/10.1016/j.mssp.2015.06.005.

15. M. Kapur, K. Soni and K. Kohli, Adv. Tech. Biol. Med., 5, 1 (2017); https://doi.org/10.4172/2379-1764.1000198.

16. S.R. Senthilkumar and T. Sivakumar, Int. J. Pharm. Pharm. Sci., 6, 461 (2014).

17. M. Sundrarajan, S. Ambika and K. Bharathi, Adv. Powder Technol., 26, 1294 (2015); https://doi.org/10.1016/j.apt.2015.07.001. 
18. D. Suresh, P.C. Nethravathi, Udayabhanu, H. Nagabhushana, H. Rajanaika and S.C. Sharma, Mater. Sci. Semicond. Process., 31, 446 (2015); https://doi.org/10.1016/j.mssp.2014.12.023.

19. B.N. Patil and T.C. Taranath, Int. J. Mycobacteriol., 5, 197 (2016); https://doi.org/10.1016/j.ijmyco.2016.03.004.

20. P. Rajiv, S. Rajeshwari and R. Venckatesh, Spectrochim. Acta A Mol. Biomol. Spectrosc., 112, 384 (2013); https://doi.org/10.1016/j.saa.2013.04.072.

21. L.F.A.A. Raj and E. Jayalakshmy, Orient. J. Chem., 31, 51 (2015); https://doi.org/10.13005/ojc/310105.

22. H. Agarwal, S.V. Kumar and S. Rajeshkumar, Resour. Efficient Technol., 3, 406 (2017); https://doi.org/10.1016/j.reffit.2017.03.002.

23. J. Sujatha, S. Asokan and S. Rajeshkumar, J. Microbiol. Biotechnol. Food Sci., 7, 348 (2018); https://doi.org/10.15414/jmbfs.2018.7.4.348-352.

24. C. Malarkodi, S. Rajeshkumar, K. Paulkumar, G. Gnanajobitha, M. Vanaja and G. Annadurai, Bioinorg. Chem. Appl., Article ID 347167 (2014); https://doi.org/10.1155/2014/347167.

25. K. Elumalai and S. Velmurugan, Appl. Surf. Sci., 345, 329 (2015); https://doi.org/10.1016/j.apsusc.2015.03.176.

26. M. Ramesh, M. Anbuvannan and G. Viruthagiri, Spectrochim. Acta A Mol. Biomol. Spectrosc., 136, 864 (2015); https://doi.org/10.1016/j.saa.2014.09.105.
27. K. Elumalai, S. Velmurugan, S. Ravi, V. Kathiravan and S. Ashokkumar, Spectrochim. Acta A Mol. Biomol. Spectrosc., 143, 158 (2015); https://doi.org/10.1016/j.saa.2015.02.011.

28. R. Yuvakkumar, J. Suresh, A.J. Nathanael, M. Sundrarajan and S.I. Hong, Mater. Sci. Eng. C, 41, 17 (2014); https://doi.org/10.1016/i.msec.2014.04.025.

29. G. Sathishkumar, C. Rajkuberan, K. Manikandan, S. Prabukumar, J. Danieljohn and S. Sivaramakrishnan, Mater. Lett., 188, 383 (2017); https://doi.org/10.1016/j.matlet.2016.11.100.

30. B. Malaikozhundan, B. Vaseeharan, S. Vijayakumar, K. Pandiselvi, M.A.R. Kalanjiam, K. Murugan and G. Benelli, Microb. Pathog., 104, 268 (2017); https://doi.org/10.1016/j.micpath.2017.01.029.

31. W. Salem, D.R. Leitner, F.G. Zingl, G. Schratter, R. Prassl, W. Goessler, J. Reidl and S. Schild, Int. J. Med. Microbiol., 305, 85 (2015); https://doi.org/10.1016/j.ijmm.2014.11.005.

32. S.C. Sharma, Int. J. Light Electron Opt., 127, 6498 (2016); https://doi.org/10.1016/j.ijleo.2016.04.036.

33. S. Vijayakumar, B. Malaikozhundan, S. Shanthi, B. Vaseeharan and N. Thajuddin, Microb. Pathog., 107, 88 (2017); https://doi.org/10.1016/j.micpath.2017.03.019.

34. S. Rajeshkumar, S.V. Kumar, A. Ramaiah, H. Agarwal, T. Lakshmi and S.M. Roopan, Enzyme Microb. Technol., 117, 91 (2018); https://doi.org/10.1016/j.enzmictec.2018.06.009. 